\title{
Absorption of decabromodiphenyl ether and other organohalogen chemicals by grey seals (Halichoerus grypus)
}

\author{
Gareth O. Thomas* ${ }^{1}$, Simon E.W. Moss ${ }^{2}$, Lillemor Asplund ${ }^{3}$ \& Ailsa J. Hall ${ }^{2}$ \\ ${ }^{1}$ Department of Environmental Science, Institute of Environmental and Natural \\ Sciences, Lancaster University, Lancaster LA1 4YQ, UK \\ ${ }^{2}$ Sea Mammal Research Unit, Gatty Marine Laboratory, St Andrews University, St \\ Andrews, Fife, KY16 8LB, UK \\ ${ }^{3}$ Institute of Applied Environmental Chemistry, Stockholm University, SE-106 91 \\ Stockholm, Sweden \\ * - author for correspondence (e-mail: g.o.thomas@lancaster.ac.uk; Tel: +44 1524 \\ 510214; Fax: +44 1524 593985)
}

\begin{abstract}
An input-output balance study was performed for polybrominated diphenyl ethers, polychlorinated biphenyls and some organochlorine pesticides on three captive, juvenile grey seals (Halichoerus grypus). The animals were fed a diet of herring for six months, during the last three months of which this study was performed. A supplement of decabromodiphenyl ether was included in the diet during the second month of the study. Consistently high absorption (>89\%) was observed for all of the chemicals studied, whereas work on other animals has generally shown high (>80\%) net absorption at log $\mathrm{K}_{\mathrm{OW}}<\sim 6$, dropping towards higher $\log \mathrm{K}_{\mathrm{OW}}$, and very low absorption of decabromodiphenyl ether. The half-life of decabromodiphenyl ether in blood was
\end{abstract}


estimated to be between 8.5 and 13 days. Measurable concentrations of decabromodiphenyl ether were detected in seal blubber at the end of the study, indicating that this chemical can be stored in adipose and may bioaccumulate. Current understanding of the mechanism of absorption of organohalogen chemicals and the potential for accumulation of decabromodiphenyl ether will need reassessing in the light of these results.

\section{Introduction}

Of the three main technical mixtures in use, the pentabromodiphenyl ether (PeBDE) and octabromodiphenyl ether (OcBDE) mixtures are currently being phased out in Europe but are still in high use in other parts of the world. However, in the UK in particular, stringent fire retardancy regulations for furniture led to previously high use of PeBDE. The decabromodiphenyl ether (DeBDE) mixture, a high usage flame retardant (approx. 54,800 tonnes annual usage estimated in 1999 (Alaee et al., 2003)), is currently undergoing a comprehensive risk assessment in the European Union (EU, 2002). This chemical is seen as a very useful flame retardant for use in electrical equipment housing, rubber insulating materials and other applications. However, there is some uncertainty over the possibility of DeBDE entering the environment, and if it does so, whether it is available to biota. The DeBDE mixture almost entirely comprises BDE 209, which has a high octanol-water partition coefficient ( $\left.\mathrm{K}_{\mathrm{OW}}\right)$, a relatively high molecular weight (959 amu) and is relatively labile to heat and light (Söderström et al., 2003). PBDEs from the PeBDE mixture have been reported in a wide range of environmental media (de Wit, 2002), and concentrations in human breast milk have recently been reported to be substantially higher in North America than in Europe 
(Petreas et al, 2003). DeBDE, despite it’s higher usage, has only been found in a small number of environmental studies, generally linked to sediments near sites of production and use (Sellström et al., 1998, Allchin et al., 1999), and, recently, in the eggs of wild birds of prey in Scandinavia (Lindberg et al., 2004), although laboratory studies have generally shown low or negligible absorption by animals (El Dareer et al., 1987; Mörck and Klasson Wehler, 2001). However, Sandholm et al. have reported that about 26\% BDE-209 was bioavailable in rats and suggested that the relatively high concentrations of phenolic metabolites present in the blood plasma compared to the parent BDE-209 indicated that total adsorption was higher than 26\%. (Sandholm et al., 2003). Jakobsson et al. (2003) have reported up to $36 \mathrm{pmol}$ BDE-209/g lipid in the blood of occupationally exposed workers.

Polychlorinated biphenyls (PCBs) and many organochlorine pesticides (OCPs) have been banned or restricted in many countries since the 1970 s due to their bioaccumulative and persistent properties, and have been dropping in concentration in many environmental media for the last two decades or so (e.g. Bignert et al., 1998). However, there are concerns about the concentrations of these chemicals in the marine environment (Tanabe, 1988; Aguilar et al., 2002), and recent work has highlighted the possibility that these chemicals may increase carcinogenic effects on biota at doses much lower than previously thought (Kalantzi et al., 2004).

Very high concentrations of PBDEs, PCBs and OCPs have been recorded in a range of marine mammals (Aguilar et al., 2002; Law et al., 2002). Organohalogen contamination has been implicated in endocrine disruption effects, leading to increased susceptibility to a range of diseases, some of which have been seen as epizootic episodes in recent years (Oberdörster and Cheek, 2000). Recently, PBDEs have been shown to affect 
thyroid hormone activity in mammals (Fowles et al., 1994; Meerts et al., 1998), and we have recently reported a correlation between PBDE and thyroid hormone levels in North Sea grey seals (Hall et al., 2003).

\section{Materials and Methods}

Study design and sampling - An input-output balance study was performed on three captive (wild) juvenile grey seals (Halichoerus grypus). The seals were fed a constant diet of North Sea herring for 3 months before this study started, by which time we anticipated that steady-state conditions, with respect to the chemicals of interest found in the diet, would have been approached. This study then lasted 3 months, during which fish were all taken from one frozen batch caught in the North Sea, defrosted as necessary. Each seal consumed between 1 and $2.5 \mathrm{~kg}$ (fresh weight) fish per day. In the second month of the study the seals were fed a supplement of $12 \mu$ g decabromodiphenyl ether per day, dissolved in cod liver oil in a capsule, and in the final month the seals were fed a control (unspiked) cod liver oil capsule each day. On a weekly basis fish samples (3 fish) were taken from the defrosted fish batch, a blood sample was taken and a 24 hour faeces sample was collected whilst each seal was kept in an individual dry enclosure. A blubber biopsy was taken from each seal at three times during the study. Chemical analysis - Samples were analysed for a range of PCBs, OCPs and PBDEs using methods based on those previously published (Thomas et al., 1998; Hovander et al., 2000; Bayen et al., 2003), which briefly entailed the following. Whole fish were ground separately in a steel blender and frozen until analysis. Fish, faeces or blubber samples were mixed well with anhydrous sodium sulphate before dichloromethane (DCM) extraction using an accelerated solvent extraction system. Blood samples were modified with hydrochloric acid and extracted with a mixture of hexane and MTBE, 
then partitioned with aqueous $\mathrm{KOH}$ to remove phenolic chemicals. All samples were spiked with seven ${ }^{13} \mathrm{C}$-labelled PCBs and ${ }^{13} \mathrm{C}$-labelled BDE 209 before extraction. Fish, faeces and blubber samples were cleaned-up on a column containing silica gel modified with concentrated sulphuric acid, eluted with hexane. Blood samples were cleaned-up using concentrated sulphuric acid. All samples received a secondary clean-up using gel permeation chromatography before being concentrated to a small volume with internal standards added. PBDEs (except BDE 209) were analysed on a Fisons MD800 GC-MS in SIM mode, with separation on a $30 \mathrm{~m}$ long, $0.18 \mathrm{~mm}$ id, DB5 MS column. The mass spectrometer was used in ECNI (electron capture negative ion) mode with ammonia as the reagent gas. PCBs and OCPs were analysed on a Thermo Trace GC-MS in SIM mode using an EI+ source. Separation was achieved on a $50 \mathrm{~m} 0.25 \mathrm{~mm}$ id CP-Sil 8 column. BDE 209 was analysed on a HP6890 GC attached to a VG Autospec Ultima used in EI+ mode, with a resolution of at least 10,000. Separation was achieved on a 15 m long, $0.18 \mathrm{~mm}$ id, DB5 MS column.

The method detection limit was defined as the higher of three times the standard deviation of the blank values or the instrument detection limit. Recoveries averaged 67 $-81 \%$ for each of the ${ }^{13} \mathrm{C}$ labelled standards.

\section{Results and Discussion}

Calculation of apparent absorption A range of PCBs, OCPs and PBDEs were found in the herring and faeces; daily input and output fluxes were calculated for each seal, for each chemical which was found. The geometric mean concentration in fish (9 samples analysed) was used to calculate the input fluxes because the concentrations determined appeared to follow a log-normal distribution. Faeces concentrations were used to 
calculate output fluxes directly for the relevant day. Chemical concentrations found in fish are shown in Table 1, and the input and output fluxes are shown in Table 2. The apparent amount of each chemical absorbed from the diet was defined as the difference between the input and output fluxes, and is expressed as a percentage of the total input flux, for a selection of the chemicals, in Table 3. Because of the log-normal distribution of chemical concentrations normally found in biota (for which there was some evidence in this study) the data were log-transformed before calculation of the apparent absorption using the formula presented by Juan et al. (Juan et al., 2002). Apparent absorption may be an over- or under-estimate of true absorption, because of the possibility of degradation within the gastro-intestinal tract or excretion of chemicals from previous exposure. BDE 209 was not found in the fish analysed, and apparent absorption was calculated solely for the occasions when this chemical was added to the diet.

Observation on apparent absorption Consistently high absorption (>89\%) of all chemicals analysed was observed. This extended over a log $\mathrm{K}_{\mathrm{OW}}$ range from approximately 3.8 (alpha-HCH) to 10.3 (BDE 209). This contrasts with work on fish (Gobas et al., 1993) and dairy cows (McLachlan, 1994; Thomas et al., 1999), showing a reduction in absorption efficiency with increasing $\mathrm{K}_{\mathrm{OW}}$ once $\log \mathrm{K}_{\mathrm{OW}}$ exceeds approximately 6. There are several possible explanations for the consistently high absorption seen in these seals:

1) The high total body fat content of seals, compared to most land animals, will provide a large capacity for storage of these hydrophobic chemicals, keeping the chemicals in the blood (the supplying medium) at a constant relatively low concentration, and creating a relatively large fugacity gradient between the gastro- 
intestinal (GI) tract contents and the blood (the receiving medium). Assuming that absorption is a purely passive process, this will cause the equilibrium between the GI tract content and blood to be consistently in favour of movement to the blood, i.e. that consistently high absorption is maintained.

2) Seals, being carnivores, generally have a high assimilation efficiency (AE) from their diet. A high AE implies that the organic matter content (and hence the fugacity capacity) of the GI tract contents is greatly reduced compared to the food, and passive transport across the GI tract wall would be in favour of movement to the blood. Herbivores and omnivores, which most previous mass balance and absorption studies have used, have a lower AE, because their diet is less digestible. They are likely to have a higher GI tract content fugacity capacity, and a lower POPs absorption efficiency. In this study the AE (dry matter) was found to be $96.9 \pm 2.3 \%$.

3) Incomplete collection of faeces, or reduced faeces output (due to increased stress in the faeces collection period) may have caused the total output flux to be underestimated. However, in any 24 hour faeces collection period it is estimated that not more than $10 \%$ of the faeces produced was lost due to dispersion by rainwater or by the seals behaviour. Comparison of the $\mathrm{AE}$ found in this study to $\mathrm{AE}$ values for herring eaten by ringed and harp seals (Lawson et al., 1997a; 1997b) suggests that the seals produced at least $50 \%$ of the faeces which might have been expected in each collection period.

4) It has been suggested that POPs can be degraded in the GI tract, which would result in an overestimation of net absorption. It is possible that this happened in this study, but we found no evidence in the concentrations of lower brominated BDE congeners in faeces, which remained constant, to suggest that it may have occurred. 
Transfer of BDE 209 to blood and body-fat - Blood BDE 209 concentrations are shown in Figure 1. BDE 209 was not detected in blood before the seals were fed the spiked capsules, nor was it found in blood after three days of BDE 209 consumption. Measurable concentrations of BDE 209 had been reached in all three seals by day 45, and the concentrations remained measurable for the remainder of the study. Maximum concentrations of BDE 209 were found in the blood between 5 and 11 days after cessation of spiked capsule consumption, and these maxima were followed by a rapid drop in BDE 209 concentrations in each seal. On day 83 BDE 209 concentrations had dropped to between 14 and 15\% of the maximum concentration for each seal. Fitting first order reaction curves to the BDE 209 concentration data for each seal, from day 59 to the end of the study, gave BDE 209 half-lives in blood between 8.5 and 13 days. BDE 209 was found in the blubber of two of the seals within 3 days of them starting to ingest DeBDE-spike capsules, and was found in all three seals at the end of the study, 29 days after the seals had ingested the last DeBDE-spiked capsule. No BDE 209 was found in blubber at the beginning of the study. The total body-fat content was estimated roughly mid-way through the study by an isotope dilution method, using deuterated water, that has been described elsewhere (Reilly and Fedak, 1990). The total bodyburdens for each seal, estimated by multiplying the blubber concentration by the estimated total body-fat content, are shown in Table 4. It can be seen that at the end of the study between 11 and 15\% of the cumulative amount of BDE 209 ingested by each seal ( $\sim 320 \mu$ g per seal) was stored in the blubber after 29 days on a DeBDE-free diet, but that after 3 days ingesting DeBDE a larger proportion of the cumulative amount of BDE 209 ingested was found in the blubber of two of the seals. BDE 209 was not detected in the blubber of seal 2 on day 30, although it was detected in the other two 
animals. Seal 2 had $10.7 \mathrm{~kg}$ of body-fat, compared to 6.3-6.4 kg for the other seals. The probable explanation for the difference between the seals is that the BDE 209 absorbed in the first few days will have been diluted into this bigger fat store, giving lower concentrations which were below the method detection limit.

Implications for risk assessments There are some important implications for the environmental and human risk assessment of BDE 209 and other non-ionised chemicals from this study.

1) It has been assumed that non-ionised non-nutrient molecules with a molecular mass of more than 700 amu cannot cross biological membranes (Mörck and Klasson Wehler, 2001). However, we cannot find convincing reports of this being true in the literature, and suggest that this assumption requires reassessment in the light of the high absorption of BDE 209 seen in this study.

2) This study shows that BDE 209 can be stored in the blubber of grey seals if they are exposed to it, although it generally appears not to be present in marine animals in the natural environment. BDE 209 has, however, been found to be present in the eggs of birds of prey (Lindberg et al., 2004) and has been found at low concentrations in salmon (Burreau, 2001). BDE 209 has also been found in sediments from some locations (Allchin et al., 999). Exposure to and absorption of BDE 209 is likely to be dependent on the species, food web and a combination of the ingested matrix with which the chemical is associated and the specific characteristics of the animal involved. For example, BDE 209 attached to organic rich sediment ingested by bottom dwelling fish is likely to be absorbed less than BDE 209 present in the bodies of the prey species of the fish. We believe that the cod liver oil used in this study 
should be a comparable carrier to whole fish, since if BDE 209 were present in fish it would most likely be contained within the fish lipids.

3) BDE 209 has been shown to be readily metabolised or excreted in other animals (e.g. Mörck and Klasson Wehler, 2001; Sandholm et al., 2003; Sjödin et al., 1999; Kierkegaard et al., 1999; Stapleton et al., 2003; Hagmar et al., 2000). Blood concentrations of BDE 209 in the seals dropped rapidly after the maximum concentration was reached, which may be due to continued transfer to the blubber or metabolism, or a combination of both. BDE 209 would probably not be metabolised appreciably whilst stored in the blubber. Thus, animals may continue to carry a bodyburden of BDE 209 after exposure, even though concentrations in the blood may rapidly become undetectable. In the wild, compounds stored in the blubber are likely to be re-mobilised during periods of fasting.

\section{References}

Alaee, M., Arias, P., Sjodin, A., Bergman, Å., 2003. An overview of commercially used brominated flame retardants, their applications, their use patterns in different countries/regions and possible modes of release. Environ. Int. 29, 683-689

Allchin, C.R., Law, R.J., Morris, S., 1999. Polybrominated diphenyl ethers in sediments and biota downstream of potential sources in the UK. Environ. Pollut. 105, 197-207

Aguilar, A., Borrell, A., Reijnders, P.J.H., 2002. Geographical and temporal variation in levels of organochlorine contaminants in marine mammals. Marine Environ. Res. 53, 425-452

Bayen, S., Thomas, G.O., Lee, H.K., Obbard, J.P. 2003. Occurrence of polychlorinated biphenyls and polybrominated diphenyl ethers in green mussels (Perna viridis) from Singapore, southeast Asia. Environ. Toxicol. Chem. 22, 2432-2437 
Bignert, A., Olsson, M., Persson, W., Jensen, S., Zakrisson, S., Litzén, K., Eriksson, U., Häggberg, L., Alsberg, T. 1998. Temporal trends of organochlorines in Northern Europe, 1967-1995. Relation to global fractionation, leakage from sediments and international measures. Environ. Pollut. 99, 177-198

Braekevelt, E., Tittlemier, S.A., Tomy, G.T. 2003. Direct measurement of octanol-water partition coefficients of some environmentally relevant brominated diphenyl ether congeners. Chemosphere 51, 563-567

Burreau, S. 2001. On the uptake and biomagnification of PCBs and PBDEs in fish and aquatic food chains. Stockholm University Thesis ISBN: 91-87272-85-7

de Wit, C.A. 2002. An overview of brominated flame retardants in the environment. Chemosphere 46, 583-624

El Dareer, S.M., Kalin, J.R., Tillery, K.F., Hill, D.L., J. 1987. Disposition of decabromobiphenyl ether in rats dosed intravenously or by feeding. Toxicol. Environ. Health 22, 405-415

EU. 2002. European Union Risk-Assessment Report Vol.17. Bis(pentabromophenyl) ether [decabromodiphenyl ether],Publication: EUR 20402 EN, European Commission

Fowles, J.R., Fairbrother, A., Baecher-Steppanc, L., Kerkvliet, N.I., 1994. Immunologic and endocrine effects of the flame-retardant pentabromodiphenyl ether (DE-71) in C57BL/6J mice. Toxicology 86, 49-61

Gobas, F.A.P.C., McCorquodale, J.R., Haffner, G.D., 1993. Intestinal absorption and biomagnification of organochlorines. Environ. Toxicol. Chem. 12, 567-576

Hagmar, L., Sjödin, A., Höglund, P., Thuresson, K., Rylander, L., K., Bergman, Å. 2000. Biological half-lives of polybrominated diphenyl ethers and 
tetrabromobisphenol A in exposed workers. Organohalogen Compounds 47, 198-201

Hall, A.J., Kalantzi, O.I., Thomas, G.O. 2003. Polybrominated diphenyl ethers (PBDEs) in grey seals during their first year of life - are they thyroid hormone endocrine disrupters? Environ. Pollut. 126, 29-37

Hawker, D.W., Connell, D.W. 1988. Octanol-water partition coefficients of polychlorinated biphenyl congeners. Environ. Sci. Technol. 22, 382-287

Hovander, L., Athanasiadou, M., Asplund, L., Jensen, S., Wehler, E.K. 2000. Extraction and cleanup methods for analysis of phenolic and neutral organohalogens in plasma. J. Anal. Toxicol. 24, 696-703

Jakobsson, K., Thuresson, K., Höglund, P., Sjödin, A., Hagmar, L., Bergman, Å. 2003. A summary of exposures to polybrominated diphenyl ethers (PBDEs) in Swedish workers and determination of half-lives of PBDEs. Organohalogen Compounds 61, $17-20$

Juan, C-Y., Green, M., Thomas, G.O. 2002. The statistical merits of various methods of calculating transfer factors between environmental media - Development of the ideal formula for data-sets with a log-normal distribution. Chemosphere 46, 1091-1097

Kalantzi, O.I., Hewitt’ R., Ford' K.J., Cooper, L., Alcock’ R.E., Thomas' G.O., McMillan, T.J., Jones, K.C., Martin, F.L. 2004. Low-dose induction of micronuclei by lindane. Carcinogenesis 25, 613-622 [doi:10.1093/carcin/bgh047 - online Dec. 19th 2003]

Kierkegaard, A., Balk, L., Tjärnlund, U., De Wit, C., Jansson, B., 1999. Dietary uptake and biological effects of decabromodiphenyl ether in rainbow trout (Oncorhynchus mykiss). Environ. Sci. Technol. 33, 1612-1617

Law, R.J., Allchin, C.R., Bennett, M.E., Morris, S., Rogan, E. 2002. Polybrominated diphenyl ethers in two species of marine top predators from England and Wales. 
Chemosphere 46, 673-681

Lawson, J.W., Miller, E.H., Noseworthy, E. 1997a. Variation in assimilation efficiency and digestive efficiency, of captive harp seals (Phoca groenlandica) on different diets. Can. J. Zool. 75, 1285-1291

Lawson, J.W., Hare, J.A., Noseworthy, E., Friel, J.K. 1997b. Assimilation efficiency of captive ringed seals (Phoca hispida), fed different diets. Polar Biol. 18, 107-111

Lindberg, P., Sellström, U., Häggberg, L., de Wit, C.A. 2004. Higher brominated diphenyl ethers and hexabromocyclododecane found in eggs of Peregrine Falcons (Falco peregrinus) breeding in Sweden. Environ. Sci. Technol. 38, 93-96

Mackay, D., Shiu, W.Y., Ma, K.C. 1992. Illustrated Handbook of Physical-Chemical Properties and Environmental Fate for Organic Chemicals. I. Monoaromatic Hydrocarbons, Chlorobenzenes and PCBs Lewis, Boca Raton, USA.

McLachlan, M.S. 1994. Hydrophobic contaminants in cows. Environ. Sci. Technol. 28, $2407-2414$

Meerts, I.A.T.M., Marsh, G., van Leeuwen-Bol, I., Luijks, E.A.C., Jakobsson, E., Bergman, Å., Brouwer, A. 1998. Interaction of polybrominated diphenyl ether metabolites (PBDE-OH) with human transthyretin in vitro. Organohalogen Compounds 37, 309-312

Mörck, A., Klasson Wehler, E. 2001. Metabolism of decabromodiphenyl ether (BDE209) in the rat. Organohalogen Compounds 52, 9-12

Oberdörster, E., Cheek, A.O. 2000. Gender benders at the beach: endocrine disruption in marine and estuarine organisms. Environ. Toxicol. Chem. 20, 23-36

Petreas, M., She, J.W., Brown, F.R., Winkler, J., Windham, G., Rogers, E., Zhao, G.M., Bhatia, R., Charles, M.J. 2003. High body burdens of 2,2',4,4 '-tetrabromodiphenyl 
ether (BDE-47) in California women. Environ. Health Perspect. 111, 1175-1179

Reilly, J.J., Fedak, M.A., 1990. Measurement of the body composition of living gray seals by hydrogen isotope dilution. J. Appl. Physiol. 69, 885-891

Sandholm, A., Emanuelsson, B.M., Klasson-Wehler, E. 2003. Bioavailability and halflife of decabromodiphenyl ether (BDE-209) in rat. Xenobiotica 33, 1149-1158

Sellström, U., Kierkegaard, A., De Wit, C., Jansson, B. 1998. Polybrominated diphenyl ethers and hexabromocyclododecane in sediment and fish from a swedish river. Environ. Toxicol. Chem. 17, 1065-1072

Sjödin, A., Hagmar, L., Klasson-Wehler, E., Kronholm-Diab, K., Jakobsson, E., Bergman, Å. 1999. Flame retardant exposure: polybrominated diphenyl ethers in blood from Swedish workers. Environ. Health Perspect. 107, 643-648

Söderström, G., Sellström, U., de Wit, C.A., Tysklind, M. 2004. Photolytic debromination of decabromodiphenyl ether (BDE209) Environ. Sci. Technol. 38, $127-132$

Stapleton, H.M., Alaee, M., Letcher, R.J., Baker, J.E., 2003. Debromination of decabromodiphenyl ether by juvenile carp (Cyprinus carpio). Organohalogen Compounds 61, 21-24

Tanabe, S. 1988. PCB problems in the future: foresight from current knowledge. Environ. Pollut. 50, 5-28

Thomas, G.O., Sweetman, A.J., Parker, C.A., Kreibich, H., Jones, K.C., 1998. Development and validation of methods for the trace determination of PCBs in biological matrices. Chemosphere 36, 2447-2459

Thomas, G.O., Sweetman, A.J.,, Jones, K.C., 1999. Input-output balance of PCBs in a long-term study of lactating dairy cows. Environ. Sci. Technol. 33, 104-112 


\section{Acknowledgements}

Financial support for this project was provided by the UK Natural Environment Research Council (grant NER/B/S/2001/00341). The Royal Society provided an overseas study grant to GT. 
Table 1 - Concentrations of chemicals in fish

\begin{tabular}{|c|c|c|c|}
\hline & $\begin{array}{l}\text { Median concentration } \\
\text { (min-max) }\end{array}$ & & $\begin{array}{c}\text { Median concentration } \\
\text { (min-max) }\end{array}$ \\
\hline & ng/g lipid & & ng/g lipid \\
\hline PCB18 & $1.3(0.46-2.4)$ & alpha-chlordane & $5.2(2.7-8.7)$ \\
\hline PCB28 & 2.7 (1.1-4.7) & alpha-HCH & 3.5 (1.8-6.7) \\
\hline PCB31 & $1.9(0.74-4)$ & HCB & $11(5.1-19)$ \\
\hline PCB44 & $2.4(0.86-4.3)$ & p,p'-DDD & $9.2(4.6-18.1)$ \\
\hline PCB49 & $1.5(0.58-3.3)$ & p,p'-DDE & 35 (8.8-88) \\
\hline PCB52 & $5.4(1.7-8.8)$ & p,p'-DDT & $3.5(1.4-11)$ \\
\hline PCB70 & $3.7(1.2-7.5)$ & & \\
\hline PCB74 & $2.2(0.85-4.3)$ & BDE28 & $1.8(1.1-2.8)$ \\
\hline PCB90 + 101 & $9.2(3.6-25)$ & BDE32 & $1.5(1.2-2.7)$ \\
\hline PCB95 & $5.3(2-12)$ & BDE35 & $1.3(1.1-1.4)$ \\
\hline PCB99 & $4.2(1.2-11)$ & BDE47 & 4.9 (1.1-10.9) \\
\hline PCB105 & $2.6(0.71-6.2)$ & BDE49 & $2.3(1.7-6.3)$ \\
\hline PCB110 & $6.3(1.8-17)$ & BDE99 & $2.7(0.83-5.4)$ \\
\hline PCB118 & $7.7(2.2-20)$ & BDE100 & $3.1(1.8-7.2)$ \\
\hline PCB132 & $2.8(1.1-9)$ & BDE153 & $1.1(1-1.1)$ \\
\hline PCB138 & $21(5.8-60)$ & BDE154 & $0.93(0.92-1.3)$ \\
\hline PCB149 & $11(4.7-32)$ & Total BDE & $17(3.3-33)$ \\
\hline PCB151 & $3.3(1.9-9.6)$ & & \\
\hline PCB153 & $20(6.5-57)$ & & \\
\hline PCB170 & $2.2(0.77-5.9)$ & & \\
\hline PCB174 & $1.7(0.77-3.5)$ & & \\
\hline PCB180 & 3.1 (1.5-8.9) & & \\
\hline PCB183 & $1.1(0.69-3)$ & & \\
\hline PCB187 & $5.9(2.1-18)$ & & \\
\hline PCB194 & $0.67(0.36-1)$ & & \\
\hline PCB203 & $0.76(0.38-1.3)$ & & \\
\hline Total PCB & $130(49-360)$ & & \\
\hline
\end{tabular}


Table 2 - Input and output fluxes of selected chemicals for all seals throughout the study

\begin{tabular}{|c|c|c|}
\hline & $\begin{array}{c}\text { Input flux } \\
\text { ng/day } \\
\text { median (min-max) }\end{array}$ & $\begin{array}{c}\text { Output flux } \\
\text { ng/day } \\
\text { median (min-max) }\end{array}$ \\
\hline alpha-HCH & $530(350-880)$ & 2.2 (nd-22) \\
\hline p,p'-DDD & $1420(940-2390)$ & $10(1-76)$ \\
\hline PCB28 & $400(270-670)$ & 1.5 (nd-17) \\
\hline p,p'-DDE & $5530(3670-9220)$ & $270(13-650)$ \\
\hline HCB & $1570(1050-2620)$ & $63(3.2-170)$ \\
\hline PCB52 & $730(490-1220)$ & $22(0.8-69)$ \\
\hline BDE28 & $270(180-450)$ & nd (nd-5.7) \\
\hline alpha-chlordane & $760(510-1270)$ & 1.4 (nd-36) \\
\hline p,p'-DDT & $550(360-920)$ & $16(0.6-69)$ \\
\hline PCB90 + 101 & $1580(1050-2630)$ & $40(1.7-130)$ \\
\hline BDE49 & $340(220-560)$ & 3.5 (nd-41) \\
\hline PCB118 & 1250 (830-2080) & $11(0.4-69)$ \\
\hline BDE47 & $620(410-1040)$ & 37 (1.5-190) \\
\hline PCB138 & $3240(2150-5410)$ & $260(13-620)$ \\
\hline PCB153 & $3200(2120-5340)$ & $280(17-780)$ \\
\hline BDE100 & $440(290-720)$ & 4.5 (nd-35) \\
\hline BDE99 & $380(250-640)$ & 5.6 (nd-38) \\
\hline PCB180 & $560(360-920)$ & $59(5.1-210)$ \\
\hline BDE153 & $150(99-250)$ & 2.0 (nd-10) \\
\hline BDE154 & $170(110-280)$ & 1.7 (nd-7.5) \\
\hline
\end{tabular}


Table 3 - Average net absorption measured throughout the study.

\begin{tabular}{|c|c|c|}
\hline & $\log K_{\mathrm{OW}}$ & \% average absorption (lower - upper standard error) \\
\hline alpha-HCH & $3.81^{\mathrm{a}}$ & $99(99-100)$ \\
\hline p,p'-DDD & $5.50^{\mathrm{a}}$ & $99(99-100)$ \\
\hline PCB 28 & $5.67^{b}$ & $99(99-100)$ \\
\hline p,p'-DDE & $5.70^{\mathrm{a}}$ & $97(94-98)$ \\
\hline HCB & $5.77^{\mathrm{a}}$ & $97(95-98)$ \\
\hline PCB 52 & $5.84^{\mathrm{b}}$ & $98(96-99)$ \\
\hline BDE28 & $5.94^{c}$ & $99(98-100)$ \\
\hline alpha-chlordane & $6.00^{\mathrm{a}}$ & $99(99-100)$ \\
\hline p,p'-DDT & $6.20^{\mathrm{a}}$ & $98(96-99)$ \\
\hline PCB $90+101$ & $6.38^{b, d}$ & $98(97-99)$ \\
\hline BDE49 & $6.60^{\mathrm{c}, \mathrm{e}}$ & $98(96-99)$ \\
\hline PCB 118 & $6.74^{\mathrm{b}}$ & $99(99-100)$ \\
\hline BDE47 & $6.81^{\mathrm{c}}$ & $95(90-97)$ \\
\hline PCB 138 & $6.83^{b}$ & $94(91-96)$ \\
\hline PCB 153 & $6.92^{b}$ & $93(89-96)$ \\
\hline BDE100 & $7.24^{c}$ & $99(98-99)$ \\
\hline BDE99 & $7.32^{c}$ & $98(97-99)$ \\
\hline PCB 180 & $7.36^{b}$ & $91(85-95)$ \\
\hline BDE154 & $7.82^{c}$ & $98(97-99)$ \\
\hline BDE153 & $7.90^{\mathrm{c}}$ & $97(95-98)$ \\
\hline BDE 209 & $10.33^{\mathrm{c}, \mathrm{e}}$ & $89(57-97)$ \\
\hline
\end{tabular}

Note that BDE 209 was fed dissolved in cod liver oil, other chemicals were naturally present in the fish diet; a = from Mackay et al., 1992; b = measured by Hawker and Connell (1988); c = from Braekevelt et al., 2003; d = log Kow value for PCB 101 used; e = calculated from Hawker and Connell, 1988 
Table 4 - Estimated total body-burden of BDE 209 at the middle and end of the study

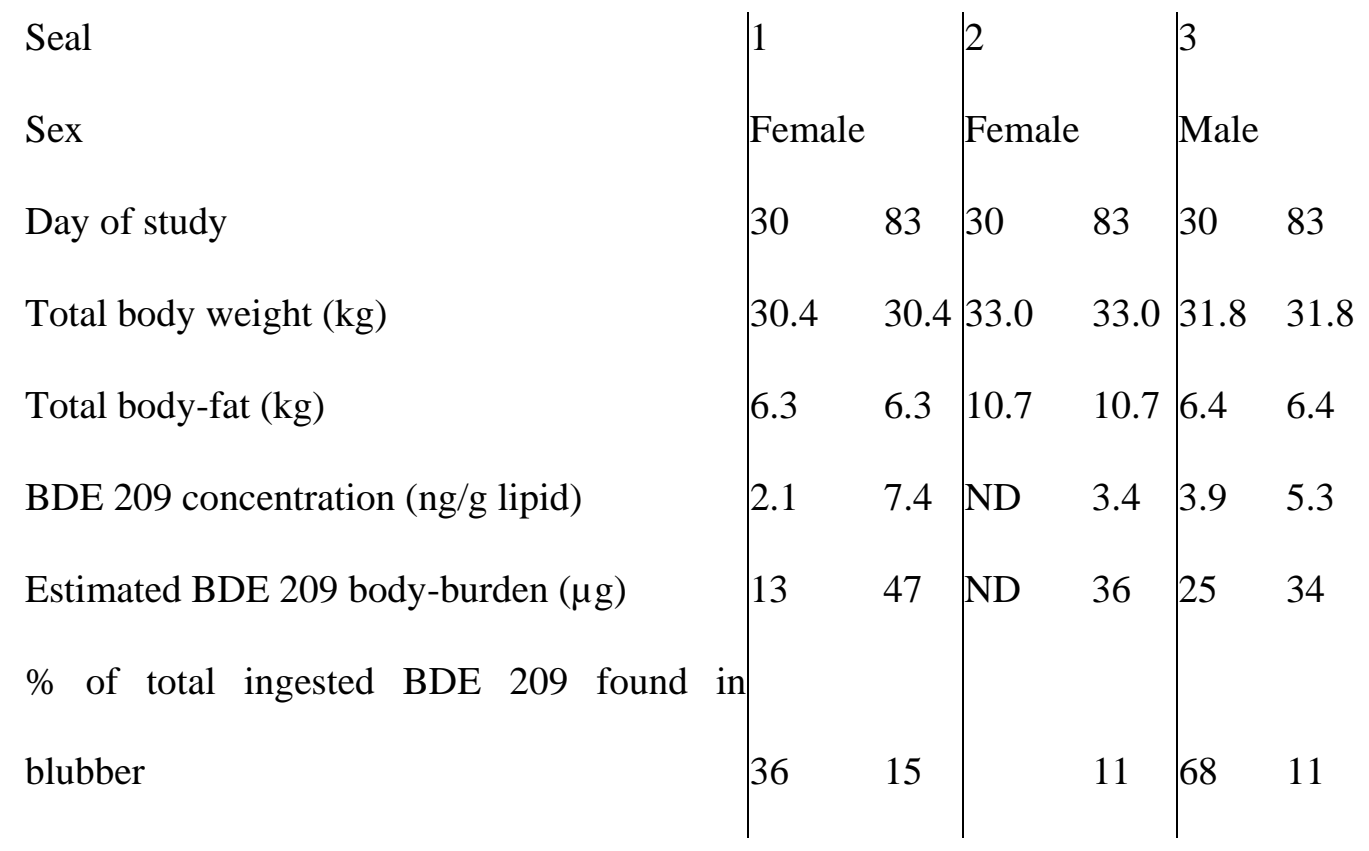

ND = BDE 209 not detected in blubber; DeBDE was fed from day 27 until day 54 


\section{List of figures}

Figure 1 -Concentration of BDE 209 in blood lipid throughout the study 
Figure 1

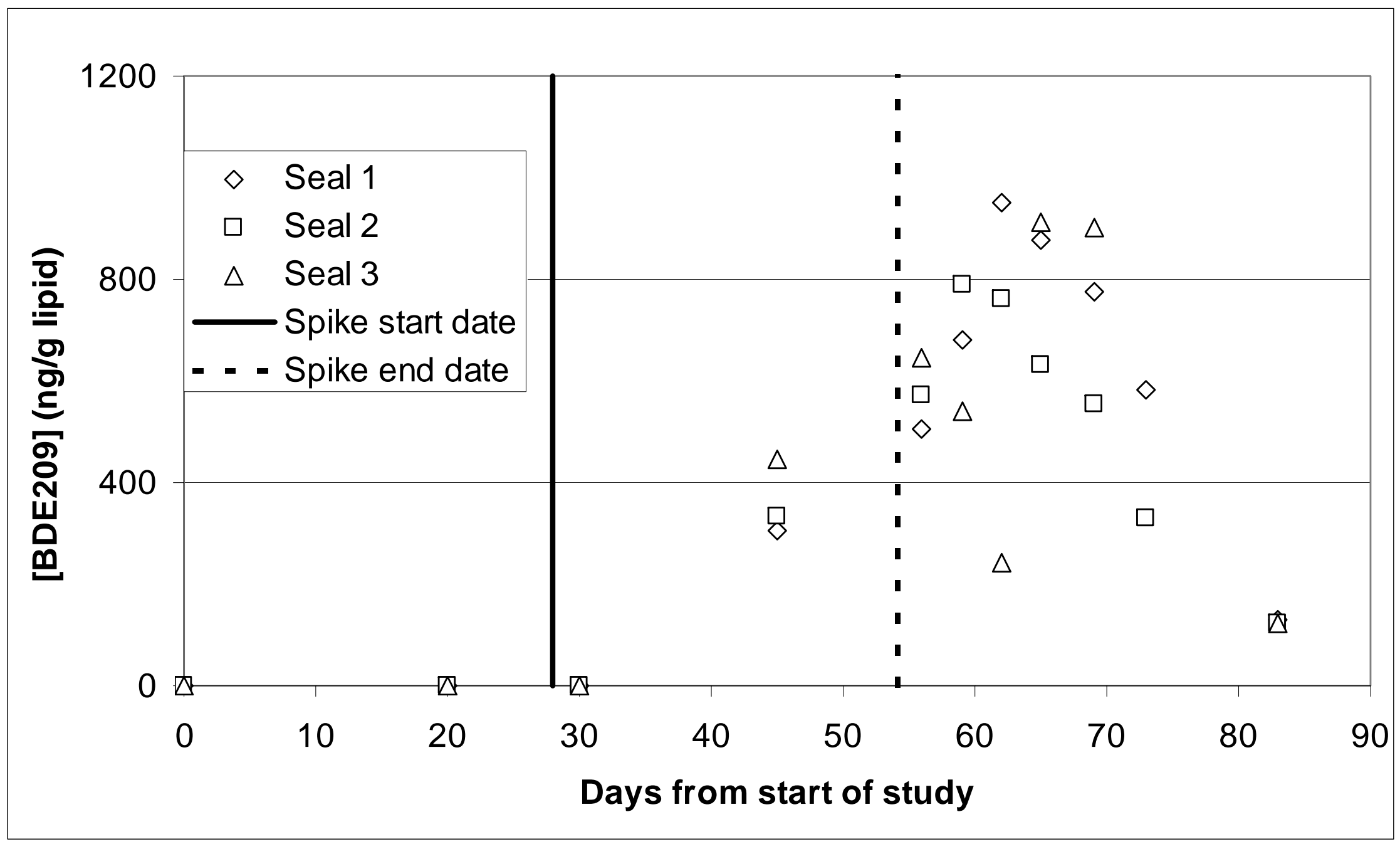

